\title{
An Evaluation of Relationship between Risk, Return and Social Structure and their Impact on Individual Investor's Behaviour at Pakistan Stock Exchange
}

\author{
Sumair Farooq ${ }^{1 *}$ \\ Syed Shabib ul Hassan ${ }^{2}$ \\ Khalid Mehmood Iraqi ${ }^{3}$
}

\begin{abstract}
This research paper focusing on two fold purposes: where the first part focuses on providing positive evidence on the nature of relationship between risk and return. Moreover, the second part of the paper deals with analysing the role of risk and return and social structures on the investor's behaviour in specific consideration with Pakistan Stock Exchange (PSX) (formerly Karachi Stock Exchange; KSE). This research paper has employed a quantitative approach for the purpose of collection of data and analysis of the results in order to fulfil the aim and objectives of the study. The data for risk and return has been collected from secondary sources. The risk and return for 50 companies that are listed on Pakistan Stock Exchange and at least once paid dividend have been calculated for 11 years which is from 2007 to 2017. Moreover, in order to collect the data for social structure and investor behaviour the researcher has used survey questionnaire as the research instrument. The questionnaire was filled by 558 individual investors who have invested their capital in the stock of companies listed on Pakistan Stock Exchange. The sampling method that was used for the purpose of selecting respondents for getting the questionnaires filled was non-probability method. For all the independent variables the null hypotheses are rejected thus showing significance of relationship. The results from the regression analysis has shown that among all the predicting variables social structure explains the lowest amount of variation in investor's behaviour. Thus, overall it can be said that the results of this study are in alignment with the previous researches.
\end{abstract}

Keywords: Risk, Return, Investor's Behaviour, Stock Exchange.

1- Department of Public Administration, University of Karachi, email: sumair_farooq@hotmail. com

2- Department of Public Administration, University of Karachi.email: sshassan@uok.edu.pk

3- Department of Public Administration, University of Karachi.email: khalid.iraqi@uok.edu.pk

Page | 184 
IBT Journal of Business Studies Volume 15(1), 2019

\section{Introduction}

One of the common dilemma which is being faced by the portfolio managers as well as individual investors is the preference of trade-off between risk and return. Investors do not seek risk while making an investment is considered to be the general consensus and convention in the domain of finance and economics. However, it is reasonable to assume that risk is a major factor that predicts the amount of returns that are received by an investor on a common stock (Hoffman and Post, 2017). The purpose of this paper is not merely to examine the risk and return on different common stocks. There is already enough literature that can be found regarding risk and return of different financial assets with different perspectives and contrasting views. There are certain studies which have been carried out to examine the relationship between risk and return. However, there is relatively less amount of literature available regarding the risk and return preferences of an individual (Baker, Hargrove, and Haslem, 1977). In order to fill this gap of the available literature, this research has been conducted to analyse the relationship between risks and return preferences of an individual. The trading behaviour of individuals has always been a topic of interest for academicians and financial analysts globally. In capital market research, behavioural finance has emerged as the domain which focuses on analysing and evaluating the behavioural component of investors (Baker and Haslem, 2015). The purpose of this research paper is two-fold where the first part focuses on providing positive evidence on the nature of relationship between risk and return. Moreover, the second part of the paper deals with analysing the role of risk and return and social structures on the investor's behaviour in specific consideration with Pakistan Stock Exchange.

The stock market can be viewed as the platform of human interactions (Hirschey and Nofsinger, 2008) where investors tend to interact with their relative, friends, and neighbours. Information is exchanged and stocks are discussed by individual. In the stock market people tend to seek information from analysts and planners and bankers. Thus, it can be said that the investment decisions of an individual can be termed as a complex behaviour that can be influenced by the irrational and rational factors that contributes to the inefficiency of security market. There are certain behaviour biases which contributes significantly towards the inefficiency of markets. Behavioural finance majorly deals with analysing the determinants and factors of the trading behaviour of individual investors. The analysis of previous studies have shown that social interaction and structure tends to contribute towards individual exhibiting irrational behaviour. There are common mistakes made by the investors due to social interaction and media. There are two roles which are played by media that influences the investor's behaviour where the first one is setting stage for market moves and instigating them (Shiller, 2000). The second role played by the media is increasing the trading frequency of individuals (Barber et al., 2000). This paper is being directed in such a manner that the influence of social structure along with the risk and return have been evaluated on the trading behaviour of investors.

There are a number of researches that have been carried out regarding understanding the individual investor behaviour and the nature of investment portfolio. There are certain researches who have applied theoretical models for the purpose of predicting and explaining the human behaviour with regard to investment in common stock. Previous researchers have evaluated social factors such as personality traits and social attitudes (Azjen, 1988; Campbell, 1963; Sherman and Fazio, 1983). From the critical evaluation of the previous researches it has been found that the most commonly used theoretical models are Theory of Planned behaviour (TPB) (Azjen, 1985; 1991) and Theory of Reasoned Action (TRA) (Fishbein and Azjen, 1975). TRA has depicted that there are two determinants of behavioural intention: attitude and subjective norms. Attitude has been termed as 
the negative or positive feelings of executing the target behaviour. On the other hand, the subjective norms are termed as perception of an individual that most people who are regarded as important think that behaviour in question should not be performed. Overall, this theoretical model infers that family members, friends, social norms, and opinion leaders play an important role in the behaviour and decision making process of an individual. The limitation of TRA is fulfilled by TPB because it deals with behaviour over which people has incomplete volition control (Azjen, 1991). TPB is considered to be the extension of TRA and hence is considered to be a more reliable model in predicting the investor's behaviour. It should be noted that irrespective of the wide range of journal articles regarding risk and return and social factor's influence on investing behaviour of individual there is very little evidence available with respect to Pakistan. In order to fulfil this gap this study has been conducted in accordance with the aforementioned objectives specifically on Pakistan Stock Exchange.

\section{Study Objective}

This study is intended to conduct the research on Pakistan Stock Exchange where risk, return and social structure are having the relationship between them and also have impact on investor's behaviour over there.

\section{Significance of the Study}

Pakistan Stock Exchange is an essential platform for investors in Pakistan. Investors keenly invest their savings as well as their capital in order to get higher profits. This study will not only analyse the relationship between risk, return and social structure but also evaluate their impact on investor's behaviour at Pakistan Stock Exchange.

\section{Research Methodology}

This research paper has employed a quantitative approach for the purpose of collection of data and analysis of the results in order to fulfil the aim and objectives of the study. The purpose of this study is to find out the relationship between risk and return and social structure and their impact on the investor's behaviour at Pakistan Stock Exchange (PSX) (formerly Karachi Stock Exchange; KSE). Considering the nature of the aim where relationship and impact is to be found, quantitative study is the most suitable approach. Quantitative study allows the researcher to obtain data that is numeric in nature and hence is standardised in nature. As this study is carried out with the help of quantitative design hence positivism research philosophy has been used (Hughes and Sharrock, 2016). Positivism is a research approach that has helped the researcher with respect to backing the findings and results of this research with logic and scientific evidence. It should be noted that positivism paradigm is generally used when quantitative and numerical data is used for the study. Considering the research design and philosophy, the approach of this research paper is deductive. The researcher has aimed at finding out the relationship and impact of risk and return and social structure on investor's behaviour in Pakistan Stock Exchange hence the following hypothesis have been tested:

$\mathrm{H} 1=$ There is a significant relationship between risk, return, and social structure with the investor's behaviour in Pakistan Stock Exchange (PSX)

$\mathrm{H} 2=$ There is a significant impact of risk, return, and social structure on the investor's behaviour in Pakistan Stock Exchange (PSX)

Considering that this research paper focuses on testing out the aforementioned hypotheses, the most suitable approach is deductive approach. According to Sekeran and Bougie (2016) deductive approach in a research facilitates the testing of hypothesis based on the collected data. It has been mentioned in the introductory section that this research paper aims to find out relationship of risk and return and social structure on the investor's behaviour hence it is suitable to test this relationship 
with the available data. It is important to discuss the data which is used for the purpose of carrying out the study. In the preceding section, it has been mentioned that the data used for the study is quantitative in nature however, there are two sources of data: primary data and secondary data. The data for risk and return has been collected from secondary sources. The risk and return for 50 companies, listed on Pakistan Stock Exchangeand at least once paid dividend, have been calculated for 11 years which is from 2007 to 2017. Moreover, in order to collect the data for social structure and investor behaviour the researcher has used survey questionnaire as the research instrument (same questionnaire has also been used in the researcher's dissertation). Survey questionnaire is an effective research tool with the help of which large amount of data can be collected in less amount of time (Moser and Kalton, 2017). The questionnaire was filled by 558 individual investors who have invested their capital in the stock of companies listed on Pakistan Stock Exchange.

The sampling method that was used for the purpose of selecting respondents for getting the questionnaires filled was non-probability method. This method is suitable because it allows the researcher to select respondents without having to give individual in population an equal chance to participate (Atikan, Musa, and Alkassim, 2016). The survey questionnaire was designed in such a manner that firstly there were certain questions related to the demographics and then there were asked regarding relationship between risk, return and social factors and their impact on investing behaviour. These questions were based on Likert scale in order to obtain numerical responses. The researcher has used statistical data analysis techniques in order to evaluate the data. The independent variables of the study are 'risk', 'return', and 'social structure' and the dependent variable is 'investor's behaviour'. The researcher has made use of correlation analysis for finding out the relationship between independent variables and dependent variable. The impact of 'risk', 'return', and 'social structure' on 'investor's behaviour' is evaluated with the help of regression analysis. A similar research methodology has also been used by the research carried out by Shanmugham and Ramya (2012) where the study was carried out for the purpose of evaluating the social factors on individual investor's trading behaviour. The methodology used for the research is in compliance with the time constraints and budget constraints.

\title{
Variables
}

\section{Independent Variables:}

1. Risk

2. Return

3. Social Structure

\section{Dependent Variables:}

\author{
1. Investor's Behaviour
}

\section{Results and Findings}

In this section of the research paper, the findings obtained from the statistical evaluation have been presented and evaluated. Considering the nature of the data and aim and objectives of the paper, two hypotheses are tested. In the first part, correlation analysis has been carried out for finding out the relationship between return, risk, and social structure with the behaviour of investors. In order to determine the relationship between aforementioned variables, subsequent hypotheses have been formed: 
$\mathrm{HO}=$ There is no significant relationship between risk and investor's behaviour in PSX $\mathrm{H} 1=$ There is a significant relationship between risk and investor's behaviour in PSX $\mathrm{HO}=$ There is no significant relationship between return and investor's behaviour in PSX $\mathrm{H} 2=$ There is a significant relationship between return and investor's behaviour in PSX $\mathrm{HO}=$ There is no significant relationship between social structure and investor's behaviour in PSX $\mathrm{H} 3=$ There is a significant relationship between social structure and investor's behaviour in PSX

Table 1.

Correlation Matrix

\begin{tabular}{|l|l|l|l|}
\hline S.no & Independent Variables & Investor's Behaviour & \\
\hline & & $\begin{array}{l}\text { Pearson Correlation } \\
\text { Coefficient }\end{array}$ & Sig (2-tailed) \\
\hline 1 & Risk & $0.530^{* *}$ & 0.000 \\
\hline 2 & Return & $0.602 * *$ & 0.000 \\
\hline 3 & Social Structure & $0.492 * *$ & 0.000 \\
\hline
\end{tabular}

Note: Correlation is significant at the 0.01 level (2-tailed)

Source: Author's Illustration

The above table shows the value of Pearson correlation coefficient for all the independent variables and dependent variables of the model. The significance level selected for this model is at $90 \%$. This infers that in order to deem the relationship between the predicting factor and dependent factor as significant, the sig value should be less than 0.01. After checking the sig value for each of the predicting variable, the coefficient of correlation should be evaluated. Weak relationship between two variables can be confirmed if the value of correlation coefficient stands below 0.30 . Moderate relationship can be stated between two variables if the value of correlation coefficient stands between 0.30 till 0.70 . Any value exceeding 0.70 shows that there is existence of strong relationship among the variables. The sig value of risk is shown to be 0.000 in the above table, suggesting that the relationship between risk and investor's behaviour is statistically significant. By interpreting the value of correlation coefficient i.e. 0.530 it can be inferred that there is moderate relationship between the variables. The sig value of return is shown to be 0.000 in the above table, suggesting that the relationship between return and investor's behaviour is statistically significant. By interpreting the value of correlation coefficient i.e. 0.602 it can be inferred that there is moderate relationship between the variables. The sig value of social structure is shown to be 0.000 in the above table, suggesting that the relationship between social structure and investor's behaviour is statistically significant. By interpreting the value of correlation coefficient i.e. 0.492 it can be inferred that there is moderate relationship between the variables. For all the independent variables the null hypotheses are rejected thus showing significance of relationship. Although there is a moderate relationship between the independent variables with investor's behaviour however, return relatively has a stronger relationship with investor's behaviour when considering the investors of Pakistan Stock Exchange.

In order to find out the impact among the independent variables of the research paper (risk, return, and social structure) with investor's behaviour, the following hypotheses are formed:

$\mathrm{HO}=$ There is no significant impact of risk on investor's behaviour in PSX 
$\mathrm{H} 4=$ There is a significant impact of risk on investor's behaviour in PSX

$\mathrm{HO}=$ There is no significant impact of return on investor's behaviour in PSX

$\mathrm{H} 5=$ There is a significant impact of return on investor's behaviour in PSX

$\mathrm{HO}=$ There is no significant impact of social structure on investor's behaviour in PSX

H6= There is a significant impact of social structure on investor's behaviour in PSX

Table 2.

Regression Results

\begin{tabular}{|l|l|l|l|l|l|}
\hline Model & $\begin{array}{l}\text { Unstandardized } \\
\text { Coefficients }\end{array}$ & Standard Coefficients & t value & $\begin{array}{l}\text { Sig at 5\% } \\
\text { level }\end{array}$ & \\
\hline & B & Std. Error & & & \\
\hline Constant & 0.967 & 0.151 & & 6.42 & 0.000 \\
\hline Risk & 0.435 & 0.046 & 0.415 & 9.454 & 0.000 \\
\hline Return & 0.202 & 0.048 & 0.203 & 4.216 & 0.000 \\
\hline Social Structure & 0.096 & 0.045 & 0.101 & 2.132 & 0.033 \\
\hline
\end{tabular}

Note: R2 $=0.407$, Adjusted R2 $=0.404$, F-statistic $=126.878$, Sig at 5\% level $=0.000$

Source: Author's Illustration

The above table has been formed in order to present the regression results in a tidy manner to interpret the impact of predicting variables and investor's behaviour in PSX. The table include important values that should be interpreted in order to assess the impact of predictors individually. The significance level selected for this model $95 \%$. This infers that in order to deem impact between the predicting factor and dependent factor as significant, the sig value should be less than 0.05 . The sig value for model that is taken into consideration is 0.000 which shows that in a collective manner all the predictors tend to explain the dependent variable. In order to assess the ability to predict the value of R2 should be interpreted which is also known as coefficient of determination. The value for the model is 0.407 which infers that risk, return, and social structure tends to explain variation caused in investor's behaviour in PSX by 40.7\%. The value of Adjusted R2 is the modified version of R2 as it is adjusted for the number of predictors in the model. For this model the value is 0.404 which means that after adjustment of number of predictors the predictors can determine $40.4 \%$ of change cause in investor's behaviour. To explain the influence of predictors separately the value of coefficient should be analysed given in the above table pertaining to their sig values. For risk, the sig value is shown as 0.000 hence at $95 \%$ significance level there is a statistical significance of impact of it on investor's behaviour. Moreover, the value of coefficient in the table is recorded to be 0.435 inferring that there will be 0.435 units increase in investor behaviour if risk is changed by a unit. For return, the sig value is shown as 0.000 hence at $95 \%$ significance level there is a statistical significance of impact of it on investor's behaviour. Moreover, the value of coefficient in the table is recorded to be 0.202 inferring that there will be 0.202 units increase in investor behaviour if return is changed by a unit. For social structure, the sig value is shown as 0.033 hence at $95 \%$ significance level there is a statistical significance of impact of it on investor's behaviour. Moreover, the value of coefficient in the table is recorded to be 0.096 inferring that there will be 0.096 units increase in investor behaviour if social structure is changed by a unit. 
IBT Journal of Business Studies Volume 15(1), 2019

\section{Reliability and Validity}

\section{Reliability}

All the variables are found reliable that is more than 0.9 which is determined through Cronbach's alpha.This result indicates a high level of internal consistency for our scale.

\section{Validity}

The validity of the scale is determined through the investors who invest their capital and savings at Pakistan Stock Exchange.

\section{Discussion}

This research has been particularly carried out for analysing the role of risk and return and social structure on the investor's behaviour pertaining to Pakistan Stock Exchange. In order to answer the fundamental research question, statistical techniques are used on the data to reach out to useful conclusions. Correlation analysis has been carried out in order to evaluate the relationship between the variables. It has been found that there is existence of relationship between all the variables. This stance is supported by the findings of the previous researches. According to the results of the study conducted by Hoffman, Post, and Pennings (2015) the risk-taking behaviour of an individual can be predicted by the perception they have regarding risk. This means that if an investor have high risk tolerance then they will invest in stock with higher risk attached to them. There is already enough literature that can be found regarding risk and return of different financial assets with different perspectives and contrasting views. Thus, from this perspective it can be said that for investors of Pakistan specifically Karachi tends to reach and behave with respect to their investment in accordance to risk and return. Another predicting variable of this study was social structure for which it has been evident from the correlation coefficient that relative to other predictors it has the lowest correlation. Irrespective of the strength of correlation, there is existence of relationship. This finding is in line with the results of the study carried out by Shanmugham and Ramya (2015) where it has been evident that social factors are related to the behaviour exhibited by investors.

Another objective of this study was to predict the role of risk, return, and social structure on the investing behaviour of investors in PSX. To fulfil this objective regression analysis has been applied on the data. The results of regression have shown that all the elements have a significant impact on investor's behaviour. The findings are also in line with previous researches carried out in this regard. The analysis of previous studies have shown that social interaction and structure tends to contribute towards individual exhibiting irrational behaviour (Barber et al., 2000). There are common mistakes made by the investors due to social interaction and media. There are two roles which are played by media that influences the investor's behaviour where the first one is setting stage for market moves and instigating them (Shiller, 2000). The results from the regression analysis has shown that among all the predicting variables social structure explains the lowest amount of variation in investor's behaviour. Thus, overall it can be said that the results of this study are in alignment with the previous researches.

\section{CONCLUSION AND RECOMMENDATIONS}

Risk, return, and social factors were found to have positive and statistically significant relationship with the investor's behaviour of the individuals who invest in Pakistan Stock Exchange. It has been found from the analysis of the results that risk and return positively predicts the investing 
behaviour. Moreover, it can be said that the investment decisions of an individual can be termed as a complex behaviour that can be influenced by the irrational and rational factors that contributes to the inefficiency of security market. There are certain behaviour biases which contributes significantly towards the inefficiency of markets.

This research has been particularly carried out for Pakistan Stock Exchange hence the results of this research cannot be generalised for other countries. Moreover, the data for risk and return has been collected for the time period ranging from 2011 to 2017. In order to carry out future researches, other countries can be selected in order to contribute significantly towards the existing body of literature.

\section{REFERENCES}

Ajzen, I. (1985). From intentions to actions: A theory of planned behavior. In Action control (pp. 11-39). Springer, Berlin, Heidelberg.

Ajzen, I. (1988). Attitudes, traits and behaviour.

Ajzen, I. (1991). The theory of planned behavior. Organizational behavior and human decision processes, 50(2), 179-211.

Baker, H. K., \& Haslem, J. A. (2015). The impact of investor socioeconomic characteristics on risk and return preferences.

Baker, H. K., Hargrove, M. B., \& Haslem, J. A. (1977). An empirical analysis of the risk-return preferences of individual investors. Journal of Financial and Quantitative Analysis, 12(3), 377389.

Barber, B. M., Lee, Y. T., Liu, Y. J., \& Odean, T. (2004, July). Who gains from trade? Evidence from Taiwan. In 12th conference on the theories and practices of securities and financial markets, Kaohsiung, Taiwan.

Bryman, A. (2016). Social research methods. Oxford university press.

Etikan, I., Musa, S. A., \& Alkassim, R. S. (2016). Comparison of convenience sampling and purposive sampling. American Journal of Theoretical and Applied Statistics, 5(1), 1-4.

Fishbein, M., \& Ajzen, I. (1975). Belief, attitude, intention and behavior: An introduction to theory and research.

Fishbein, M., \& Ajzen, I. (1980). Understanding attitudes and predicting social behavior.

Hirshey, M., \& Nofsinger, J. (2008). Investments: Analysis and Behaviour.

Hoffmann, A. O., \& Post, T. (2017). How return and risk experiences shape investor beliefs and preferences. Accounting \& Finance, 57(3), 759-788.

Hoffmann, A. O., Post, T., \& Pennings, J. M. (2015). How investor perceptions drive actual trading and risk-taking behavior. Journal of Behavioral Finance, 16(1), 94-103.

Hughes, J. A., \& Sharrock, W. W. (2016). The philosophy of social research. Routledge.

Moser, C. A., \& Kalton, G. (2017). Survey methods in social investigation. Routledge.

Sekaran, U., \& Bougie, R. (2016). Research methods for business: A skill building approach. John Wiley \& Sons.

Shanmugham, R., \& Ramya, K. (2012). Impact of Social Factors on Individual Investors' Trading Behaviour. Procedia Economics and Finance, 2, 237-246.

Shiller, R. (2000). Irrational Exuberance, Princeton Univ. 
IBT Journal of Business Studies Volume 15(1), 2019

\section{Appendix}

Table 1.

Correlation Matrix

\begin{tabular}{|l|l|l|l|}
\hline S.no & Independent Variables & Investor's Behaviour & \\
\hline & & $\begin{array}{l}\text { Pearson Correlation } \\
\text { Coefficient }\end{array}$ & Sig (2-tailed) \\
\hline 1 & Risk & $0.530^{* *}$ & 0.000 \\
\hline 2 & Return & $0.602 * *$ & 0.000 \\
\hline 3 & Social Structure & $0.492 * *$ & 0.000 \\
\hline
\end{tabular}

Note: Correlation is significant at the 0.01 level (2-tailed)

Source: Author's Illustration

Table 2.

Regression Results

\begin{tabular}{|l|l|l|l|l|l|}
\hline Model & $\begin{array}{l}\text { Unstandardized } \\
\text { Coefficients }\end{array}$ & Standard Coefficients & t value & Sig at 5\% level & \\
\hline & B & Std. Error & & & \\
\hline Constant & 0.967 & 0.151 & & 6.42 & 0.000 \\
\hline Risk & 0.435 & 0.046 & 0.415 & 9.454 & 0.000 \\
\hline Return & 0.202 & 0.048 & 0.203 & 4.216 & 0.000 \\
\hline Social Structure & 0.096 & 0.045 & 0.101 & 2.132 & 0.033 \\
\hline
\end{tabular}

Note: R2 $=0.407$, Adjusted R2 $=0.404$, F-statistic $=126.878$, Sig at 5\% level $=0.000$

Source: Author's Illustration 